\title{
In situ phase-domain calibration of oxygen Optodes on profiling floats
}

\author{
Robert Drucker ${ }^{1}$ and Stephen C. Riser ${ }^{2}$ \\ ${ }^{1}$ University of Washington <robert@ocean.washington.edu> \\ ${ }^{2}$ University of Washington <riser@ocean.washington.edu>
}

\begin{abstract}
Comparison of profiles from oxygen Optodes deployed on profiling floats with ship-based bottle casts taken at the time of deployment shows typical low biases of approximately 0 to $-40 \mu \mathrm{mol} \mathrm{kg}{ }^{-1}$. Most proposed methods to correct these biases use linear or multiplicative corrections of the derived variable $\mathrm{O}_{2}$. Some of these methods depend on specific reference data such as deployment casts or air measurements. Here, we describe a versatile in situ method to recalculate $\mathrm{O}_{2}$ directly from Optode phase and temperature by recalibrating two coefficients of the modified Stern-Volmer equation. This method may be used to calibrate most floats deployed with Optodes to date, as well as present floats, including those equipped with air measurement capability. Reference data can be taken from historic ship casts, climatology, deployment casts, and/or air measurements, depending on availability.

In situ calibrations were performed on 147 Optodes floats deployed on UW floats between 2004 and 2015 using only World Ocean Database (WOD) references. Median differences to World Ocean Atlas (WOA) 2009 climatology were reduced from $~ 6 \%$ to $\sim 1 \%$. Deployment casts were used to estimate error for eight Argo floats deployed in the Indian and Pacific Oceans; the aggregate error was reduced from $8 \%$ to $0.3 \%$

Comparison of six pairs of Optodes deployed on the same float showed relative errors after in situ calibration of $0.1 \pm 0.6 \mu \mathrm{mol} \mathrm{kg}$. . WOD-calibrated surface air oxygen values for nineteen Optode floats with air-measurement capability were compared with expected oxygen levels from NCEP surface level pressures and showed typical errors of $< \pm 2 \%$.

Using data from eight floats with deployment casts, comparison of phase-domain linear correction with oxygen-domain linear correction showed a difference of less than $\sim \pm 2 \%$. Comparison of surface gain correction with deployment casts found gaincorrected values below the depth of the oxygen minimum to be consistently low, with residuals of approximately -0.5 to $-4.5 \%$.
\end{abstract}

\section{Background}

In situ correction of oxygen Optodes has been discussed in several recent papers [Takeshita et al., 2013; D’Asaro and McNeil, 2013; Fiedler et al. 2013; Bittig and Körtzinger 2015; Bushinsky et al., 2016; Johnson et al., 2016] The methods proposed are generally either linear (2-point) or gain (1-point) corrections to oxygen values which had been previously calculated using factory calibration coefficients. While these methods generally produce useful results compared to uncorrected oxygen, they may be subject to second-order error due to the nonlinearity of the oxygen equation. Here we describe a versatile method in which we recalibrate the phase correction, determined in the lab for 
each specific Optode after a multi-Optode foil calibration, using the best available in situ reference data. Following Uchida et al. (2008), we then use the modified Stern-Volmer equation to calculate dissolved oxygen $\left(\mathrm{O}_{2}\right)$ directly from the sensor output variables phase $(\phi)$ and temperature (T). We will refer to our method as phase-domain calibration or phase correction, in contrast to oxygen-domain correction, to indicate that we apply our correction to the raw phase in $\left[\phi, \mathrm{T}, \mathrm{O}_{2}\right]$-space, rather than as a correction to the calculated oxygen. As we show below, this method can be used to calibrate most Optodes that have been deployed to date, as well as new deployments, and can easily be adapted to take advantage of floats with air measurement capabilities.

To date there have been several hundred optical oxygen sensors deployed on profiling floats throughout the world ocean. These are primarily Aanderaa 3830 and 4330 Optodes (with a smaller number of the Sea-Bird 63 Optical Dissolved Oxygen sensors now beginning to be deployed). The manufacturer (Xylem/Aanderaa Instruments AS, Bergen, Norway) specifies the accuracy of dissolved oxygen measurements using factory calibration as $<8 \mu \mathrm{mol} \mathrm{l}^{-1}$ or $5 \%$, so that for a typical near-surface $\mathrm{O}_{2}$ level of $\sim 300 \mu \mathrm{mol} \mathrm{kg}{ }^{-1}$ the specified accuracy would be $\sim 15 \mu \mathrm{mol} \mathrm{kg}^{-1}$ [Körtzinger et al. 2005]. This level of accuracy is insufficient for many research purposes. In practice, comparison of profiling float Optode oxygen profiles with shipboard bottle oxygen casts often shows discrepancies of up to $-40 \mu \mathrm{mol} \mathrm{kg}$-1 throughout the water column [Kobayashi et al., 2006, cited in Uchida et al., 2008].

Although the reason for this apparent bias is not well understood, the consistently low calibration is clearly a systemic problem rather than random measurement error. D’Asaro and McNeil (2013) found that Aanderaa 3830 Optodes lose sensitivity at predictable rates during storage and transport prior to deployment. These "storage drifts" are large and almost always negative. Once deployed, drift rates are reduced dramatically. This may be because profiling floats are almost always at their parking depth (usually $1 \mathrm{~km}$ ), in stable conditions of low temperature, oxygen and light. Bushinsky et al. (2016) measured pre- and post-deployment drifts for 14 Optodes deployed in the Kuroshio Extension and at Ocean Station Papa. They found an average storage drift rate at saturation of $-7.2 \% \mathrm{yr}^{-1}\left(\sim 20 \mu \mathrm{mol} \mathrm{kg}{ }^{-1} \mathrm{y}^{-1}\right)$ and an average postdeployment drift rate of $-0.1 \% \mathrm{yr}^{-1}\left(\sim 0.3 \mu \mathrm{mol} \mathrm{kg}{ }^{-1} \mathrm{y}^{-1}\right)$, with maximum post-deployment drifts rates of $-0.5 \% \mathrm{yr}^{-1}$. Johnson et al. (2016) find a mean post-deployment sensor drift of $\pm 0.2 \% \mathrm{yr}^{-1}$ in 29 floats in ice-free regions and conclude that this value is statistically indistinguishable from zero, so that there is no evidence that Optodes drift after deployment.

Due to the large storage drifts, laboratory calibration of Optodes cannot be reliably used for sensors deployed on profiling floats, which are rarely recovered and recalibrated. Because the Optodes only stabilize after they are deployed, they must be recalibrated in situ. In this paper we describe an in situ technique to recalibrate Optodes using a method analogous to the manufacturer's laboratory calibration.

\section{Basic calibration method}

Optode sensors employ a process called dynamic luminescence quenching. A gas permeable foil containing a platinum porphyrine complex luminophore is exposed to the surrounding water. When excited by blue-green light, the luminophore fluoresces at a 
lower energy (red light). The presence of oxygen molecules decreases both the luminescence intensity and decay time. Because luminescence intensity is affected by other factors besides oxygen, luminescence decay provides a better indication of oxygen concentration. In the Optode, the excitation light is modulated at $5 \mathrm{kHz}$, and either the decay time $\tau$ or the related phase delay $\phi=\tan ^{-1}(\omega \tau)$ is measured [Demas et al. 1999; Körtzinger et al., 2005].

Optode calibration is a two-step process. First, a general oxygen "surface" (bivariate function) is derived to map measured values of phase delay and temperature to levels of dissolved oxygen. This surface is parameterized by a number of coefficients, requiring an equal or greater number of calibration points of known phase, temperature and oxygen. For Aanderaa Optodes, the manufacturer of the platinum porphyrine sensing foil (Precision Sensing $\mathrm{GmbH}$, PreSens) supplies multiple calibration points averaged from 4 foils out of each batch of 100 . For the 3830 Optode, 35 calibration points at 7 oxygen levels and 5 temperatures are used to derive 20 coefficients for a general bivariate polynomial oxygen surface [Aanderaa Instruments, 2003]. For the 4330 Optode, 40 calibration points at 10 oxygen levels and 4 temperatures are used to calibrate either a 28 coefficient bivariate polynomial or the modified Stern-Volmer equation (Uchida et al., 2008, discussed below) [Aanderaa Instruments, 2012]. The manufacturer supplies a calibration certificate with each Optode that includes the calibration data and coefficients [see Aanderaa Instruments, 2003 or Aanderaa Instruments, 2012 for more details on the foil calibration].

The foil calibration is corrected for each Optode using a linear phase correction. This correction, which transforms raw phase delay to calibrated phase delay, is a simple linear transform based on two measurements, one in air and one in zero oxygen. The second factory calibration step, specific to each Optode, consists of finding the linear coefficients of this transform. These coefficients are applied to the raw phase before calculation of oxygen from corrected phase and temperature.

This basic two-step process is the basis of our method. However, we modify it in two substantive ways. First, following Uchida et al. (2008), we replace the bivariate polynomial oxygen surface with the modified Stern-Volmer-Uchida (hereafter, SternVolmer-Uchida) equation. The Stern-Volmer-Uchida equation specifically describes the relationship between phase delay, temperature, and oxygen concentration during dynamic fluorescence quenching and is widely accepted as the preferred oxygen equation [Uchida et al., 2008; Aanderaa Instruments, 2012; Bittig et al., 2014; McNeil and D'Asaro, 2014]. It is parameterized by only seven coefficients, two of which are analogous to the phase correction coefficients used to correct raw phase before application to the bivariate polynomial. As we show below, five of these coefficients can be found directly from the foil calibration, so that in situ calibration can follow the same two-step process as lab calibration. Second, we replace the two-point laboratory data for phase correction with analogous two-point in situ data.

\subsection{The Stern-Volmer-Uchida equation}

The relationship between luminescence decay time and oxygen concentration is described by the Stern-Volmer equation [Demas et al. 1999]. Uchida et al. (2008) described a method to use a linearly calibrated phase delay $\phi_{\mathrm{c}}=\mathrm{A}+\mathrm{B} \phi_{\mathrm{r}}$, where $\phi_{\mathrm{r}}$ is 
the raw phase shift. They showed that the ratio $\phi_{0} / \phi_{c}$ is more linearly related to oxygen concentration than $\tau_{0} / \tau$, where $\tau_{0}$ and $\phi_{0}$ are the decay time and phase delay when no oxygen is present, and proposed a modified Stern-Volmer equation to calculate oxygen concentration, given by

$$
\mathrm{O}_{2}=\frac{\phi_{0} / \phi_{\mathrm{c}}-1}{\mathrm{~K}_{\mathrm{SV}}}
$$

where:

$$
\begin{aligned}
& \mathrm{K}_{\mathrm{SV}}=\mathrm{C}_{1}+\mathrm{C}_{2} \mathrm{~T}+\mathrm{C}_{3} \mathrm{~T}^{2} \\
& \phi_{0}=\mathrm{C}_{4}+\mathrm{C}_{5} \mathrm{~T} \\
& \phi_{\mathrm{c}}=\mathrm{C}_{6}+\mathrm{C}_{7} \phi_{\mathrm{r}}
\end{aligned}
$$

$\mathrm{T}$ is temperature in ${ }^{\circ} \mathrm{C}, \phi_{\mathrm{r}}$ is the raw phase in degrees (BPhase for the 3830; TPhase for the 4330), $\phi_{c}$ is the calibrated phase, $\phi_{0}$ is the zero-oxygen phase, and $C_{1}$ through $C_{7}$ are calibration coefficients to be determined. We refer to $\left[\mathrm{C}_{1} \mathrm{C}_{2} \mathrm{C}_{3}\right]$ as the temperature coefficients, $\left[\mathrm{C}_{4} \mathrm{C}_{5}\right]$ as the zero coefficients, and $\left[\mathrm{C}_{6} \mathrm{C}_{7}\right]$ as the phase coefficients.

Note that while the ratio $\phi_{0} / \phi_{c}$ is linearly related to oxygen concentration at a specific temperature, modification of the phase coefficients, which is the basis of Optode calibration in the lab, will not generally translate to a linear change in $\mathrm{O}_{2}$. The magnitude of this nonlinearity will be examined in Section 9 below.

The first five Stern-Volmer-Uchida coefficients, $C_{1}$ through $C_{5}$, are found by fitting Eq. 1 to the foil calibration points, holding $\mathrm{C}_{6}=0$ and $\mathrm{C}_{7}=1$. The foil calibration provides zero-oxygen calibration points at five (3830) or four (4330) temperatures, so the zero coefficients can be found by linear regression:

$$
\left\{\mathrm{T}_{0}, \phi_{0}\right\} \rightarrow\left[\mathrm{C}_{4} \mathrm{C}_{5}\right]
$$

where $\mathrm{T}_{0}$ and $\phi_{0}$ are the foil test zero-oxygen temperatures and phases. Using all foil calibration points, the temperature coefficients are then found by $2^{\text {nd }}$ order regression:

$$
\begin{aligned}
& \mathrm{R}=\frac{\mathrm{C}_{4}+\mathrm{C}_{5} \mathrm{~T}_{\text {foil }}}{\phi_{\text {foil }}} \\
& \mathrm{K}_{\mathrm{SV}}=(\mathrm{R}-1) / \mathrm{O}_{2} \text { foil } \\
& \left\{\mathrm{T}_{\text {foil }}, \mathrm{K}_{\mathrm{SV}}\right\} \rightarrow\left[\mathrm{C}_{1} \mathrm{C}_{2} \mathrm{C}_{3}\right]
\end{aligned}
$$

Note that, since the zero coefficients do not depend on the temperature coefficients, the first five coefficients are found uniquely without the use of iterative fitting methods.

After finding $C_{1}$ through $C_{5}$, the phase coefficients $C_{6}$ and $C_{7}$, initially set to $[0,1]$, are recalculated. Equation 1 defines a bivariate oxygen function $\mathrm{O}_{2}=f(\mathrm{~T}, \phi)$. This can be inverted to a bivariate phase function $\phi=f^{-1}\left(\mathrm{~T}, \mathrm{O}_{2}\right)$. Reference phases 
corresponding to the reference oxygen values are found by interpolation of reference oxygen and temperature into the phase function:

$$
\phi_{\text {ref }}=f^{-1}\left(\mathrm{~T}_{\text {ref }}, \mathrm{O}_{2 \text { ref }}\right)
$$

Note that $f^{-1}$ does not need to be explicitly solved; the phases are found by interpolation. Using these values of $\phi_{\text {ref }}$ and the corresponding Optode phases $\phi_{\mathrm{r}}$, new phase coefficients are found by linear regression:

$$
\left\{\phi_{\mathrm{r}}, \phi_{\mathrm{ref}}, \mathrm{w}_{\mathrm{k}}\right\} \rightarrow\left[\mathrm{C}_{6} \mathrm{C}_{7}\right] \quad[\text { Eq. } 2 \mathrm{~d}]
$$

where weights $w_{k}$ (based on the number of reference points) may be used in the regression.

To summarize, the first five coefficients for the Stern-Volmer-Uchida equation are found algebraically from the foil test temperatures and phases using Equations $3 \mathrm{a}$ and $3 \mathrm{~b}$ To find the phase coefficients $\mathrm{C}_{6}$ and $\mathrm{C}_{7}$, vectors of reference oxygen and CTD temperature are interpolated into the phase surface to get a vector of reference phases $\left[\phi_{\text {ref }}\right]$. These are then regressed against the raw Optode phases $\left[\phi_{\mathrm{r}}\right]$ to obtain the phase coefficients.

If the foil test phases are not available, they may be easily reconstructed using the bivariate polynomial coefficients, stored in either the COCoef to C4Coef properties (3830; see Aanderaa Instruments, 2003) or FoilCoefA and FoilCoefA properties (4330; see Aanderaa Instruments, 2012). If the Stern-Volmer-Uchida equation was used for the lab calibration, the first five coefficients may be used as is.

In theory, only two Optode measurements and two corresponding reference values (at low and high oxygen) are necessary to evaluate the phase coefficients (in which case the regression in Equation $2 d$ would simply be a two-point fit.) In practice, linear regression of a larger number of points is used to reduce error. The number of points used depends on the availability of trusted reference data. If, for example, a deployment cast concurrent with the first float profile was taken, it might be enough to use two (or more) samples from that cast and profile. Usually, no deployment cast is available, so an alternative reference must be used. Because profiling floats normally sample between 2000 and 5 dbar every 10 days, over time a large number of high oxygen, high temperature samples from the surface layer and lower oxygen, low temperature samples from the deep layer are collected at different locations. By comparing these with historic shipboard bottle casts at nearby locations, garnered from the World Ocean Database (WOD09) [Johnson et al., 2009], two statistical "calibration points" analogous to low- and high-oxygen laboratory samples can be averaged as reference points.

Figure 1 illustrates the two-step calibration process used in both the factory calibration and in our method. Figure 1a shows the foil-calibration; Figure 1b shows the effect of phase correction.

Figure 1a shows part of the Stern-Volmer-Uchida oxygen surface calculated from the 35-point foil batch calibration, along with in situ data, from UW float 5092 (WMO4900487), where the phases have not been corrected. This figure corresponds to the foil batch calibration with neither laboratory nor in situ Optode-specific phase 
correction applied. The colored circles represent calculated $\mathrm{O}_{2}$ samples from 156 profiles. The colors correspond to the difference between batch-calibrated $\mathrm{O}_{2}$ and the Stern-Volmer-Uchida oxygen surface. White circles represent reference $\mathrm{O}_{2}$ samples from WOD casts along the float track. The figure shows that the foil batch-calibrated equation without phase correction is a poor fit to real data from this Optode.

Figure $1 \mathrm{~b}$ shows the surface with phase correction (in this case, using in situ data). The data now fit the surface well. Note that for both figures the first five Stern-VolmerUchida coefficients were found from the 35 lab calibration points for the foil batch; only the last two Stern-Volmer-Uchida coefficients have been modified in Figure 1b. This is analogous to the Optode manufacturer's two-point phase correction, except that in situ reference data have been used instead of pre-deployment laboratory data.

\section{Reference data}

If a deployment cast is available, finding the reference phases (Eq. 2c) is straightforward. Two samples, at low and high oxygen, are needed, although more can be used in the regression (Eq. 2d) to reduce error. It is vital that the deployment cast and float profile measure the same water column. For this reason the cast must be as close as possible in location and time to the profile; oxygen levels may change by more than the measured accuracy even in periods of $<1$ day or over spatial separations of $<1 \mathrm{~km}$, particularly near the surface. Comparison of the profile and cast CTDs should be used to judge their correspondence. Air measurements, if available, may be used in place of surface layer measurements to reduce error (see Section 8). Oxygen levels near the oxygen minimum, usually around 800-1200 dbar, are subject to large spatial and temporal variations due to vertical movement of water masses; we therefore recommend the use of reference samples from the upper mixed layer and from below $1800 \mathrm{dbar}$ (we use nominal levels of 20 and 1900 dbar.)

For most floats, no suitable deployment cast is available, so reference values are found from WOD bottle casts proximate to as many float profiles as possible. For each profile, we attempt to find one or two reference points, a high-oxygen reference near the surface and a low-oxygen reference at depth. As discussed above, mid-depth values are avoided due to vertical variability near the oxygen minimum or in the pycnocline. For reasons that will be discussed below, the deep layer point and near-surface point are handled differently.

\subsection{Deep layer reference data}

For most profiling floats, the maximum profile pressure is $\sim 2000 \mathrm{dbar}$. We use a nominal value of $1900 \mathrm{dbar}$ as the deep layer calibration point in order to include as many profiles as possible. At this depth in most locations, temperature, salinity and oxygen are relatively stable and free of seasonal and diurnal variation.

For each float profile, deep-layer T, S, and $\phi_{\mathrm{r}}$ at $1900 \mathrm{dbar}$ are found by spatial interpolation. Temperature and salinity are taken from the CTD (because of thermal mass issues, we do not use the Optode thermistor, but instead we adjust the CTD temperature to compensate any bulk offset between the CTD and thermistor.) The WOD is then searched for nearby bottle oxygen casts, and these are also interpolated to the 
nominal depth. We use potential density rather than pressure as the depth variable for interpolations of both float and reference data. That is, we calculate the potential density of the float profile at $1900 \mathrm{dbar}$ and interpolate all data to this isopycnal. Use of potential density surfaces minimizes the variability in $\mathrm{T}, \mathrm{S}$ and $\mathrm{O}_{2}$ due to vertical heaving.

After removing unwanted WOD casts (see below), the deep layer $\mathrm{O}_{2}$ values are averaged to get a reference $\mathrm{O}_{2}$ for that profile. Averaging is weighted by the distance between the float profile and each WOD cast, using a two-dimensional Gaussian function $\left(\sigma_{\text {lat }}=2^{\circ}, \sigma_{\text {lon }}=3^{\circ}\right.$, based on length scales using autocorrelations of WOCE ship transects).

A number of filters are used to select the best WOD casts. First, an elliptical region of $14^{\circ}$ radius in latitude and longitude is searched around each float profile for casts going back to 1985 . The ellipse radii are gradually increased, and the earliest year gradually decreased, until at least four casts are found, or until an ellipse of $1^{\circ}$ in each coordinate and a year limit of 1966 are reached. If no casts are found within these limits, the profile is not used for calibration.

Next, each cast is subjected to a number of tests. Any cast containing out-ofrange or missing values of temperature, salinity, pressure, or oxygen is discarded. Next, an optional temperature filter is applied: if the temperature at the deep layer point differs from the float CTD temperature by more than $0.1^{\circ} \mathrm{C}$, the cast is discarded. Next, any repeated measurements are discarded in favor of the last taken.

At this point, $\mathrm{O}_{2}$ is converted to molar units $\left(\mu \mathrm{mole}^{-1}\right)$ and decompensated for pressure and salinity (see Aanderaa Instruments, 2003 and 2012). Optode response is decreased by 3.2\% per 1000 dbar [Uchida et al., 2008]; Bittig et al., 2015 estimate the uncertainty of the pressure correction to around $0.3 \%$ per $1000 \mathrm{dbar}$.

Next, the mean and standard deviation of all deep layer casts are evaluated and $\pm 1 \sigma$ outliers are removed (if there are less than four casts, this step is omitted.) The remaining casts are averaged using Gaussian weights (see above.) The result represents one reference sample. This procedure is followed for each float profile, producing vectors of reference oxygen and temperature.

These reference vectors are then pruned. First, values outside of the $90^{\text {th }}$ percentile of $\Delta \mathrm{O}_{2}=\mathrm{O}_{2 \text { float,uncal }}-\mathrm{O}_{2 \text { ref }}$ are removed. Finally, reference points at distances greater than the $25^{\text {th }}$ percentile, or dates earlier than the $75^{\text {th }}$ percentile, are discarded.

\subsection{Surface layer reference data}

The straightforward procedure described above for the low-oxygen deep layer calibration samples is problematic in the high-oxygen region near the surface. Dissolved oxygen levels at the surface or shallow mixed layer are much more variable than those at depth. Because of this, historic reference values near the surface are much less likely to reflect the oxygen measured at a particular time and place by the float.

However, surface waters are constrained by proximity to the atmosphere to have equilibrium oxygen saturations [hereafter $\% \mathrm{O}_{2}$ Sat] near $100 \%$. This tendency can be exploited to derive reference $\mathrm{O}_{2}$ levels if we are careful to avoid $\mathrm{OO}_{2}$ Sat anomalies, such as supersaturation due to warming or biological activity in spring, or undersaturation due to cooling in late fall or winter. Boyer et al. (1999) show that winter (Jan-Mar) $\%_{2} \mathrm{O}_{2}$ Sat 
averages for the North Pacific and North Atlantic at $20 \mathrm{~m}$ depth are very near $100 \%$, while near-surface spring (Apr-Jun) and summer (Jul-Sep) averages are about $103 \%$. Najjar and Keeling (1997) attribute high supersaturation in the mixed layer in early summer to high rates of warming and high production; they cite Jenkins and Goldman (1985) and Emerson (1987) in attributing undersaturation or very low supersaturation to surface cooling and mixed-layer deepening. We assume that similar processes occur in other basins.

To get high-oxygen reference points, we use seasonal averages of $20 \mathrm{dbar}$ $\% \mathrm{O}_{2}$ Sat and calculated solubility to calculate a reference $\mathrm{O}_{2}$ :

$$
\mathrm{O}_{2_{\text {ref }}}=\mathrm{SO} \cdot \% \mathrm{O}_{2} \text { Sat } \quad[\mathrm{Eq} .3]
$$

where SO is the oxygen solubility calculated from the float CTD temperature and salinity [García and Gordon, 1992] and $\mathrm{\% O}_{2}$ Sat is a seasonal, basin-wide, latitudinal median from WOD casts from 1966 to 2009 (outliers removed). Using basin-wide latitudinal averages ensures a large database for all profiles and accounts for latitudinal variance, which is the dominant areal variation; however, it does not separate longitudinal variance (such as occurs in the eastern equatorial Pacific.)

In order to reduce errors due to supersaturation or undersaturation, profiles collected in seasons with local WOD averages greater than $101 \%$ or less than $98 \%$ are excluded in the calibration. Additionally, as for the deep layer, outliers in $\Delta \mathrm{O}_{2}$ are removed so that anomalous oxygen levels are avoided. The CTD temperature is used as the reference temperature for the surface layer point.

Although a minimum of one reference for each depth layer is required, the best results will be achieved if a larger number $\mathrm{N}$ of independent reference points are available, reducing random error by a factor $\sqrt{\mathrm{N}}$. In most parts of the world, sufficient measurements of the deep layer are available. However, because surface layer profiles can only be used in seasons where surface saturations are expected to be near $100 \%$, the float can normally only be well calibrated after it has been operating for long enough to collect such profiles. Many floats are deployed in spring or summer, when supersaturation due to biologic activity is common, so that normally calibration of these floats cannot be done until fall (unless a deployment cast is taken.) However, once sufficient suitable casts are available, the calibration will be valid for the earlier casts as well.

Once enough data are available, deep and surface layer reference data are assembled into vectors $\left[\mathrm{O}_{2 \text { ref }}\right]$ and $\left[\mathrm{T}_{\text {ref }}\right]$. Equation $2 \mathrm{c}$ is then used to convert these into a vector of reference phases $\left[\phi_{\text {ref }}\right]$, which is then regressed with the raw Optode phases $\left[\phi_{\mathrm{r}}\right]$ to determine the phase coefficients.

\section{An example: UW Float 5092}

UW float 5092 (WMO 4900487) was deployed in the Indian Ocean from the $R / V$ Roger Revelle on 11 March 2007 as part of the Climate and Ocean: Variability, Predictability and Change (CLIVAR)/Repeat Hydrography cruise I08S [Swift and Wong, 2007]. The first profile was taken at 14:34 UTC on 12 March at latitude $32.05^{\circ} \mathrm{S}$, longitude $94.98^{\circ} \mathrm{E}$. An oxygen bottle cast was performed from the ship at 13:21 UTC on 
$11 \mathrm{March}$ at latitude $32.01^{\circ} \mathrm{S}$ longitude $95.01^{\circ} \mathrm{E}, 25 \mathrm{~h}$ before, and $5.6 \mathrm{~km}$ away from the first float profile. The float continued to collect profiles in the southeastern Indian Ocean until 05 July 2011 , providing a total of 156 profiles over a range of $7.5^{\circ}$ latitude and $11^{\circ}$ longitude.

This float provides a good test case for several reasons. The float operated in a mid-latitude region, so that seasonal variation is relevant. The southeastern Indian Ocean is a relatively sparsely measured region for oxygen, although there are enough data to calibrate this float. Finally, the close proximity of the first profile with an accurate oxygen bottle cast allows us either to calibrate the Optode against the deployment cast, or to calibrate against WOD data and compare the results with the deployment cast.

For UW5092, the procedure described above yielded 26 usable deep layer WOD reference casts and 40 samples of $\mathrm{O}_{2}$ calculated from seasonal $\% \mathrm{O}_{2}$ Sat at $20 \mathrm{dbar}$. The calibration data are plotted in Figure 2 as a scatterplot of reference phase vs. Optode raw phase (BPhase.) The regression (Eq. $2 \mathrm{~d})$ and resultant phase coefficients $\left(\mathrm{R}_{1}=1.23\right.$, $\left.\mathrm{R}_{0}=-7.10\right)$ are indicated.

Figure 3 shows the float track and comparisons of factory- and in situ-calibrated $\mathrm{O}_{2}$. For a first-order evaluation (see discussion below), we compare Optode with climatology from the World Ocean Atlas (WOA09) [García et al., 2010]. WOA means were interpolated to float position, pressure, and month using Gaussian-weighted means in a manner analogous to that described in Section 2.1 above. Figure $3 \mathrm{~b}$ shows scatterplots of factory- and in situ-calibrated $\mathrm{O}_{2}$ vs. WOA $\mathrm{O}_{2}$. Figures $3 \mathrm{c}$-e show section plots of $\mathrm{O}_{2}$ from 0 to 2000 dbar. These plots show that the in situ-calibrated $\mathrm{O}_{2}$ is in good agreement with climatology.

\subsection{Comparison with deployment cast}

While comparisons with climatology (Figure 3) provide first-order validation of in situ calibration, proximate ship-based bottle casts may be used for more exact error analysis. Unfortunately, for most currently deployed Optode floats, no such casts exist. In the best cases, we have deployment casts within 1-3 days and 5-40 km of the first profile. For these displacements, it is likely that the dissolved oxygen differs significantly between the cast location/time and the profile location/time. In addition, in order to compare the two profiles they must be interpolated to a common depth. In regions of large vertical gradients of $\mathrm{O}_{2}$, this interpolation may introduce large sampling errors.

For UW float 5092, we have a high-quality oxygen bottle cast taken $\sim 25 \mathrm{~h}$ previous to and $5.6 \mathrm{~km}$ away from the first profile (CLIVAR I08S station 81). Figure 4a shows factory- and in situ-calibrated Optode oxygen profiles compared with the ship cast. Residual values $\varepsilon_{\mathrm{O}_{2}}=\mathrm{O}_{2 \text { cal }}-\mathrm{O}_{2}$ shipcast are shown alongside the plot. Figure $4 \mathrm{~b}$ shows temperature profiles from the float CTD and deployment cast, along with temperature residuals $\varepsilon_{\mathrm{T}}=\mathrm{T}_{\mathrm{CTD}}-\mathrm{T}_{\text {shipcast }}$. The temperature residuals provide an indication of the actual correspondence of the float profile and deployment cast; since the temperatures of both the float CTD and the deployment cast are accurate to better than $0.01{ }^{\circ} \mathrm{C}$, values of $\varepsilon_{\mathrm{T}}$ exceeding this value must be due either to real differences in the two water columns or to sampling error. In the case of float 5092, the temperature residuals are near the accuracy of the CTD thermistor in the deep layer and oxygen minimum layer, and within 
$0.2^{\circ} \mathrm{C}$ at most other depths. This suggests that the bottle cast measured a similar water column to that of the float profile.

The oxygen profiles reveal that the factory calibrated oxygen values for this float were low by $\sim 12.5 \mu \mathrm{mol} \mathrm{kg}{ }^{-1}$ compared with the bottle cast. After in situ calibration by the two-point phase correction described above (using WOD $\mathrm{O}_{2}$ at $1900 \mathrm{dbar}$ and seasonally averaged WOD \%02Sat at $20 \mathrm{dbar}$ ), the median residual is reduced from $-12.5 \mu \mathrm{mol} \mathrm{kg}{ }^{-1}(-6 \%)$ to $-0.3 \mu \mathrm{mol} \mathrm{kg}{ }^{-1}(-0.2 \%)$.

The profiles in Figure 4 are divided into five vertical zones, corresponding to the mixed layer, pycnocline, mid-depth, oxygen minimum layer, and deep layer. Numbers along the right side of the graph list median residual values for each vertical zone. Figure 5 shows the in situ-calibrated oxygen residuals $\varepsilon_{\mathrm{O}_{2}}$ plotted against the temperature residuals $\varepsilon_{\mathrm{T}}$ for each zone, with the median and standard deviation of both residuals indicated. All oxygen residuals are less than $1 \%$ in the mixed layer, oxygen minimum layer, and deep layer, where temperature residuals are on the order of $0.01{ }^{\circ} \mathrm{C}$. Larger oxygen residuals are seen where temperature residuals are also large, particularly in the pycnocline, where the vertical sampling frequency is low relative to density and oxygen gradients. The median residual error in the mixed layer and deep layer, where temperature residuals are very small, are $-0.15 \mu \mathrm{mol} \mathrm{kg}^{-1}(-0.06 \%)$ and $+0.23 \mu \mathrm{mol} \mathrm{kg}$ ${ }^{1}(+0.14 \%)$, respectively.

\section{Estimation of error (floats with deployment casts)}

The results for UW float 5092 suggest that, under suitable conditions (i.e., sufficient reference data), in situ phase-domain calibration can produce accuracies on the order of $0.1 \%$. However, even when a deployment cast is available, direct comparison of float $\mathrm{O}_{2}$ values with shipboard data can be a poor measure of the Optode accuracy due to either spatial and temporal differences between the cast and profile, sampling error (particularly at depths where the vertical oxygen gradient is large), uncertainty due to pressure correction, and errors inherent in shipboard Winkler titration. In order to estimate the actual error $e_{\mathrm{O}_{2}}$ throughout the water column, we note that the variance of the oxygen residuals increases with the variance of the temperature residuals, as we would expect (see Figure 5). If the deployment cast were a perfect predictor of the float profile, the temperature residuals would be zero and the oxygen residuals would be equal to the real error. Thus we can define the error as the limit of the median oxygen residuals as the temperature residuals approach zero:

$$
e_{\mathrm{O}_{2}} \equiv \lim _{\varepsilon_{\mathrm{T}} \rightarrow 0} \overline{\varepsilon_{\mathrm{O}_{2}}} \quad \text { [Eq. 4a] }
$$

where $\varepsilon_{\mathrm{O}_{2}}$ and $\varepsilon_{\mathrm{T}}$ are the oxygen and temperature residuals, respectively, between the float and deployment cast CTD and $\overline{\varepsilon_{\mathrm{O}_{2}}}$ is the median of oxygen residuals $\mathrm{O}_{2, \text { optode }}-$

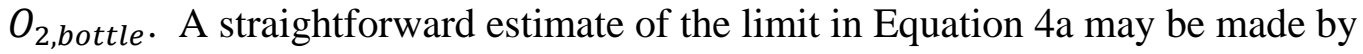
calculating the median oxygen residual only for samples where the temperature residuals are small. That is, we can estimate Equations 4a as:

$$
e_{\mathrm{O}_{2}} \approx \overline{\varepsilon_{\mathrm{O}_{2}}} ;\left|\varepsilon_{\mathrm{T}}\right|<\delta T \quad \text { [Eq. 4b] }
$$


where $\delta T$ is a very small value.

Along with UW float 5092, seven other Argo floats (UW5093, 5071, 5094, 5072, 5095, 5073, and 5100) carrying Aanderaa 3830 Optodes were deployed on CLIVAR cruise I08S in 2008. For these eight floats, deployment casts reasonably close to (4-35 $\mathrm{km}$ ) and within $\sim 1$ day of the first float profile were taken, and the floats went on to collect over 2800 profiles in the southern Indian, southwestern Pacific, and Southern oceans over the next 7 years. Figure 6 shows the trajectories and active dates for each of these floats. We applied the calibration algorithm described above for float 5092 to each of these floats, using WOD oxygen data at 1900 dbar along each float track, and deriving $20 \mathrm{dbar} \mathrm{O}_{2}$ from seasonal basin-wide latitudinal averages of $\mathrm{H}_{2} \mathrm{O}_{2}$ Sat. We also calibrated each float Optode using the deployment cast as the reference $\mathrm{O}_{2}$ at the depths nearest 20 and 1900 dbar. Table 1 lists the Stern-Volmer-Uchida phase coefficients derived for each float for each of the two calibration references.

We compare the Optode oxygen values from the first profile of each of these floats with the deployment cast and use Equation $4 b$ to estimate the error achievable by the calibration method described above. For a suitable threshold $\delta T$, we note that the nominal accuracy of Argo CTD temperature is $0.01^{\circ} \mathrm{C}$ and choose twice this value, or $\delta T=0.02^{\circ} \mathrm{C}$. In order to ensure that a temperature error of this amount will not appreciably affect the calculated value of $\mathrm{O}_{2}$, we find the partial derivative of Eq. 1 with respect to T:

$$
\delta O_{2} / \delta T=\frac{\left(\frac{\mathrm{C}_{5}}{\phi_{\mathrm{c}}}\right) \mathrm{K}_{S V}-\left(\frac{\phi_{0}}{\phi_{C}}-1\right)\left(\mathrm{C}_{2}+2 \mathrm{C}_{3} \mathrm{~T}\right)}{\mathrm{K}_{S V}{ }^{2}}
$$

From Eq. 5 we calculate $\delta O_{2}$ for $\delta T=0.02^{\circ} \mathrm{C}$ for all phase/temperature samples for the eight floats with deployment casts and find $\delta O_{2}<0.09 \%$ for $99.999 \%$ of samples. We also find that estimates derived from Equation $4 \mathrm{~b}$ are robust within this same approximate range for values $0.01^{\circ} \mathrm{C}<\delta T<0.05^{\circ} \mathrm{C}$.

Using this threshold, we use Eq. $4 \mathrm{~b}$ to estimate errors for factory, deployment cast, and WOD-based calibration for each float and for the aggregate. The results are tabulated in Table 2. The table shows that while the factory calibrations are low by 7 $14 \%$, errors for both the deployment cast- and WOD-referenced calibrations are well within $0-1 \%$, with aggregate errors of $0.2-0.3 \%$.

\section{Calibration of 147 deployed UW Optode floats}

As of July 2015, 168 profiling floats carrying Aanderaa 3830 or 4330 oxygen Optodes had been deployed by the University of Washington. We applied the above methods to recalibrate most of these instruments against WOD-based reference data, using Matlab version R2013b [MathWorks Inc., Natick, Massachusetts]. For 21 floats, recalibration could not be done due to a lack of sufficient reference data or to various sensor or float malfunctions. For the remaining 147 floats, oxygen profiles using factory and in situ calibrations were compared to WOA climatology. We use WOA here rather than WOD in order to avoid use of the calibration reference dataset, although it must be emphasized that the WOA is based on WOD and is therefore not an independent 
reference. Also, as discussed above, residual values of $\mathrm{O}_{2, \text { optode minus }} \mathrm{O}_{2 \text {,woA }}$ may be used as first-order estimates, but differences between WOA climatology and specific oxygen levels at the float profiles are potentially large, so that these estimates should be viewed only as rough indications of the calibration success. For example, in our error analysis of UW float 5092 above we estimated the error to be on the order of $0.1 \%$, while comparison with WOA (Figure 3 above) showed a median agreement of only $1.9 \%$. We view agreement with WOA of $0-3 \%$ (roughly $0-9 \mu \mathrm{mol} \mathrm{kg}{ }^{-1}$ ) to be an indication that in situ calibration was successful. Figures $7 \mathrm{a}$ and $7 \mathrm{~b}$ show histograms of median Optode minus WOA residuals (for $\Delta \mathrm{T}<0.1^{\circ} \mathrm{C}$ ). Compared to factory calibration values, the in situ calibration reduces the residuals from $-16.7 \pm 9.4 \mu \mathrm{mol} \mathrm{kg}^{-1}(\sim 6 \%)$ to $-3.1 \pm 4.1$ $\mu \mathrm{mol} \mathrm{kg} \mathrm{kg}^{-1}(\sim 1 \%)$. The cause of the remaining bias is not clear but may be present as a small bias of WOA compared to WOD. Calibrated oxygen for these floats is available at http://runt.ocean.washington.edu/o2/. The web site will also contain Matlab functions containing the calibration algorithm.

\section{Dual Optode floats}

Six UW floats were deployed in the North Pacific in 2012 and 2013, each carrying two Aanderaa 4330 Optodes. Because the two Optodes operated at the same location and depth, were initially calibrated independently, and were recalibrated against the same reference data, these dual-Optode floats allow us to measure the relative precision of the factory and in situ calibrations independently of the accuracy of the WOD reference data. Figure 8 shows scatterplots comparing in situ-calibrated oxygen for the two Optodes aboard each float (Optode 1 on float 7661 ceased operating after 24 profiles; the last profile was removed.) In situ-calibrated bias between the two Optodes on each float was $0.4 \mu \mathrm{mol} \mathrm{kg}{ }^{-1}$ or less; for five of the six floats it was $0.1 \mu \mathrm{mol} \mathrm{kg}{ }^{-1}$ or less. The standard deviation of the difference was less than $1 \mu \mathrm{mol} \mathrm{kg}-1$ for five of the six floats and 1.5 $\mu \mathrm{mol} \mathrm{kg}{ }^{-1}$ for one float. The median relative error of the six Optode pairs was $-0.1 \pm 0.6$ $\mu \mathrm{mol} \mathrm{kg} \mathrm{kg}^{-1}$.

Note that, using factory calibration, inter-Optode bias ranged from -2.1 to +2.5 $\mu \mathrm{mol} \mathrm{kg}{ }^{-1}$. These values are fairly small compared to the average storage drifts $(\sim 15$ $\mu \mathrm{mol} \mathrm{kg}{ }^{-1}$ compared to WOA) but are an order of magnitude larger than the in situcalibrated biases. Because the two Optodes on each float experienced identical environmental conditions both before and after deployment, this suggests that most, but not all, of the error using the factory calibration is attributable to storage drift. Our results also show that in situ phase-domain calibration can correct these relative errors to within $0.1 \%$.

These results are summarized in Table 3.

\section{Air measurements}

Optodes function in air as well as in water, vapor-saturated air being equivalent to air-saturated fresh water [Aanderaa Instruments, 2003, p. 32]. Bushinsky et al. (2016) describe a method to use these air measurements to correct post-deployment drift, although they caution against a simple gain correction based on Optode response over narrow temperature and oxygen ranges. Johnson et al. (2016) use gain correction from 
surface air measurements to adjust oxygen over the entire profile. We propose that the air measurements could be used in place of the surface layer (20 dbar) samples described in Section 3.2. In order to use the two-point correction described in this paper (or any linear correction), a low oxygen, low temperature calibration point must still be derived from deep-layer samples compared to ship casts.

For the purposes of this paper, air samples can be used as an independent reference to validate the accuracy of calibration done with WOD-based references. This is useful both as an independent check of the accuracy of this method (and others), and because the great majority of floats deployed to date did not provide air measurements. By examining air measurements for those floats that have this capability, we can validate our methods independently of differences between surface layer conditions at the float profile and reference conditions, which have limitations noted above.

We use air measurements to validate WOD-based calibrations on nineteen Argo floats with surface air observations deployed in the Southern and South Atlantic oceans between December 2011 and January 2015. One float, UW6967 (WMO5903612), was deployed in the South Atlantic at $42.29^{\circ} \mathrm{S}$ on $11 \mathrm{Dec} 2011$ and reported data until March 2016 (it drifted into the South Indian Ocean in the winter of 2013-14). This float provided 223 profiles of oxygen data, which we calibrated using the method described in section 3.2 above, using deep-layer reference data from $\mathrm{WOD}_{2}$ and surface-layer reference data from seasonal averages of $20 \mathrm{dbar}$ WOD $\%_{2} \mathrm{O}_{2}$ Sat. Air samples were not used in the calibration, so we may use them to validate the WOD calibrations.

Because the Optode response in vapor-saturated air is equivalent to oxygen-saturated fresh water, Equation 1 can be used to calculate equivalent fresh-water molar oxygen concentration from the Optode phase and temperature observations taken in air:

$$
O_{2 \text { equiv,optode }}=\frac{\frac{\mathrm{C}_{4}+\mathrm{C}_{5} \mathrm{~T} \text { optode }}{\mathrm{C}_{6}+\mathrm{C}_{7} \phi_{\mathrm{r}}}-1}{\mathrm{C}_{1}+\mathrm{C}_{2} \mathrm{~T}_{\text {optode }}+\mathrm{C}_{3} \mathrm{~T}_{\text {optode }}{ }^{2}} \quad \text { [Eq. 6a] }
$$

where $\phi_{\mathrm{r}}$ is the in-air Optode raw phase, $\mathrm{T}_{\text {Optode }}$ is the Optode thermistor temperature, and $\mathrm{C}_{1}-\mathrm{C}_{7}$ are the Stern-Volmer-Uchida coefficients used in the WOD-based Optode calibration. Note that we use the Optode thermistor temperature rather than the CTD, as the CTD does not extend above the surface. Also, unlike other oxygen values used in this paper, equivalent oxygen concentrations in air are given in molar units $\left(\mu \mathrm{mol} 1^{-1}\right.$ ) and are uncompensated for pressure and salinity. From the molar oxygen concentration we can then derive partial pressure:

$$
\begin{gathered}
\alpha=48.998-1.335 \mathrm{~T}+2.755 \times 10^{-2} \mathrm{~T}^{2}-3.220 \times 10^{-4} \mathrm{~T}^{3}+1.598 \times 10^{-6} \mathrm{~T}^{4} \\
\mathrm{~V}_{\mathrm{m}}=0.22414 \\
\mathrm{p}_{\text {atm }}=1013.25 \\
P_{O_{2}, \text { Optode }}=\left(\frac{\mathrm{p}_{\text {atm }} \mathrm{V}_{\mathrm{m}}}{\alpha}\right) O_{2 \text { equiv,optode }} \quad[\text { Eq. } 6 \mathrm{~b}]
\end{gathered}
$$


where $\mathrm{T}$ is Optode temperature in ${ }^{\circ} \mathrm{C}, \alpha$ is the Bunsen absorption coefficient, $\mathrm{V}_{\mathrm{m}}$ is molar volume of oxygen in $\mathrm{ml}_{\mu} \mathrm{mol}^{-1}$, and $\mathrm{p}_{\text {atm }}$ is nominal atmospheric pressure [Aanderaa Instruments, 2003 and 2012; García and Gordon, 1992].

Next, we calculate the expected partial pressure of oxygen using surface air pressure from the 6-hourly National Centers for Environmental Prediction (NCEP) reanalysis:

$$
\begin{aligned}
\mathrm{p}_{\mathrm{v}} & =\mathrm{e}^{\left[52.57-\frac{6690.9}{\mathrm{~T}+273.15}-4.681 \ln (\mathrm{T}+273.15)\right]} \\
P_{O_{2, N C E P}} & =0.20946\left(\mathrm{p}_{N C E P}-\mathrm{p}_{\mathrm{v}}\right) \quad \text { [Eq. 6c] }
\end{aligned}
$$

where $\mathrm{p}_{N C E P}$ are NCEP surface level pressures interpolated to the float positions, $\mathrm{p}_{\mathrm{v}}$ is vapor pressure in $\mathrm{hPa}$, and 0.20946 is the volume fraction of $\mathrm{O}_{2}$. Because of the proximity of the air measurements to the sea surface, and the difficulty of extending 10-m NCEP humidity data to the surface, we assume a relative humidity of $100 \%$. Figure $9 \mathrm{a}$ shows $P_{O_{2} \text { optode }}$ and $P_{O_{2}, N C E P}$ for UW float 6967. The partial pressures derived from WOD-calibrated Optode oxygen agree well with the expected values derived from NCEP pressures, with a mean error of $-0.8 \pm 1.2 \%$.

This float drifted from the South Atlantic, where the average surface oxygen and temperature were $\sim 340 \mu \mathrm{mol} \mathrm{l}^{-1}$ and $\sim 11^{\circ} \mathrm{C}$, respectively, into the Indian Ocean, where they were $\sim 280 \mu \mathrm{mol}^{-1}$ and $\sim 20^{\circ} \mathrm{C}$. In order to show how the calibration tracks across this large range of oxygen and temperature levels, we calculate an equivalent molar oxygen concentration for $P_{O_{2}, N C E P}$ :

$$
O_{2 \text { equiv,NCEP }}=\left(\frac{\alpha}{\mathrm{p}_{N C E P} V_{\mathrm{m}}}\right) P_{O_{2, N C E P}} \quad \text { [Eq. 6d] }
$$

where $\mathrm{p}_{N C E P}$ is the NCEP surface level pressure in $\mathrm{hPa}$. This value is the molar $\mathrm{O}_{2}$ concentration in fresh water that would be equivalent to the NCEP partial pressure $P_{O_{2, N C E P}}$ in air. Figure $9 \mathrm{~b}$ shows the equivalent molar concentrations $O_{2}$ equiv,optode and $\mathrm{O}_{2}$ equiv,NCEP.

We repeated these calculations for nineteen UW floats with air measurements (Table 4). All of these floats operated in or near the Southern Ocean. For most of these floats the median air measurement error was less than $\pm 1.5 \%$. Floats 0068 and 9275 had larger air measurement errors, but these floats also had large errors relative to WOA surface layer climatology, indicating that the calibration was not successful.

Another float, UW 6968 (WMO 5903718), shows a large standard deviation in the air measurement error (the float was deployed in the Southern Ocean in March 2012 and stopped reporting in September 2015). This may indicate an abnormally large drift in the Optode calibration. As mentioned above, typical post-deployment drift has been estimated to be < 0.3 $\mu \mathrm{mol} \mathrm{kg}{ }^{-1} \mathrm{y}^{-1}$ [Bushinsky et al., 2016; Johnson et al., 2016], but some Optodes may have greater drift. Because calibration against WOD requires the reference to be averaged over relatively long periods, Optode drift, if it exists, is problematic. We correct each Optode with a single pair of phase coefficients, which we assume are minimally changed over time. If this assumption does not hold, the 
calibration will need to change with time. Where good-quality independent surface level data are available, air measurement may provide a way to check for calibration drift (Figure 9c). Use of air measurements for the high-oxygen calibration point may also provide a way to make periodic corrections for sensor drift, although this capability has yet to be fully developed.

\section{Comparison with alternative methods}

A number of alternative methods to correct Optodes in situ have been proposed. Takeshita et al., 2013 used both a 2-point (linear) correction and 1-point (gain) correction in the oxygen domain. More recent papers (Bushinsky et al., 2016; Johnson et al., 2016) have introduced methods to correct Optode storage drift and long-term drift using simple gain-correction methods based on air oxygen measurements taken at the surface, as described above in Section 8. Rather than using the air measurement as one of two in situ calibration points, as we do, these papers propose a simple one-point gain correction. Bittig and Körtzinger, 2015 argue that the large storage drifts seen in most Optodes prior to deployment may be mostly due to a reduction in $\mathrm{O}_{2}$ sensitivity, manifest as a change in the Stern-Volmer temperature-dependent term $\mathrm{K}_{\mathrm{SV}}$ (Eq. 1a), with a much smaller effect due to a change in the zero coefficients $\left[\mathrm{C}_{4} \mathrm{C}_{5}\right]$ (Eq. 1b) [Bittig and Körtzinger, 2015; see also discussions in McNeil and D'Asaro, 2014]. Assuming a proportional reduction in sensitivity independent of temperature (note that temperature variation over the profile is often quite large), this may be largely accounted for by a single multiplicative correction or by a combination of gain and offset. This method has the advantage of being extremely simple to implement, provided that a reliable reference oxygen is available at at least one point in the profile. Bushinsky et al., 2015 and Johnson et al., 2016 implement this correction in profiling floats with air measurements, so that the point of correction is at the surface (normally at the highest oxygen level).

In this section we compare these approaches to the method described in this paper. In Section 9a we compare linear correction in the phase domain with linear correction in the oxygen domain; in Section $9 \mathrm{~b}$ we compare linear corrections with gain correction.

9a. Comparison of phase-domain and oxygen-domain linear correction

The physical causes and characteristics of storage drift are not yet well understood. In situ revision of the Stern-Volmer-Uchida phase coefficients may be a practical way to compensate for post-deployment change [Aanderaa Instruments, 2012, pp. 53-55; Uchida et al., 2008]. Although recalculating oxygen with modified Stern-Volmer parameters is computationally less straightforward than simply applying a linear correction to oxygen (on top of the factory calibration), we fear that the latter may add error because of nonlinearity and temperature dependency of the oxygen calculation. Revising the oxygen equation with in situ data allows us to recalculate oxygen directly from the sensor variables, phase and temperature. However, we are constrained in situ to two degrees of freedom, so that we must retain the foil calibration, while recalibrating only the Optode- 
specific phase coefficients. This approach follows the two-step process described by Uchida et al., 2008, though other approaches may be feasible.

The practical difference between phase-domain and oxygen-domain linear correction is difficult to establish because its magnitude is likely quite small and may be less than other variations in either the calibrations themselves or in the references available for validation. Even in the few cases where we have ship deployment casts, temporal and spatial differences of those casts with the nearest float profile often limit their correspondence to greater than $\sim 1 \%$. Nevertheless, we may use the CLIVAR I08S floats discussed in Section 5 above to gain some measure of the magnitude of the difference between phase and oxygen correction.

To this end, we performed a linear correction in the oxygen domain for the eight CLIVAR I08 floats. Using the same in situ reference oxygen values as we did for the phase calibration (i.e., getting reference $\mathrm{O}_{2}$ from $\% \mathrm{O}_{2}$ Sat at $20 \mathrm{dbar}$ and WOD DO at 1900 dbar), we regressed the reference oxygen set with uncorrected oxygen to establish a single pair of linear coefficients for each Optode. This is identical to the phase correction procedure described in Sections 2 and 3, except that the linear coefficients are in oxygen space and are applied to the factory-corrected oxygen profiles (recall that in phasedomain linear correction we use phase-domain references to calculate linear coefficients to correct the raw Optode phase delay, and then use these corrected phases, along with temperature, to recalculate oxygen).

- Figures 10a and 10b show the residuals (converted to percent) of linear-corrected oxygen minus the deployment cast for oxygen-domain and phase-domain correction, respectively. Pressure-binned medians and $\pm 1 \sigma$ for the eight floats are shown. Both methods compare favorably with the deployment cast. Overall, the oxygen-domain linear correction residuals are $-0.12 \pm 3.0 \%$, while those for phase-domain linear correction are $-0.02 \pm 2.9 \%$. The phase-domain residuals are slightly smaller than the oxygendomain residuals in the mixed layer $(-0.05 \pm 0.5 \%$. vs. $+0.40 \pm 1.1 \%$ for $\mathrm{P}<50 \mathrm{dbar})$ and below the thermocline $(+0.10 \pm 0.8 \%$. vs. $+0.49 \pm 1.0 \%$ for $\mathrm{P}>1000 \mathrm{dbar})$. Figure $10 \mathrm{c}$ shows the percent difference between oxygen-domain linear correction and phasedomain linear correction for the eight floats. Over all pressures, the methods differ by $+0.3 \pm 0.8 \%$.

9b. Comparison of linear and gain correction

To compare linear correction with gain correction, we implement a variant of surface gain correction for the eight CLIVAR I08S floats. While these floats did not provide in-air observations, the ship casts performed at deployment provide us with a similar high-oxygen reference from the uppermost mixed-layer sample (nominally 5 dbar). We use this sample to calculate a single scalar gain correction for each float:

$$
\begin{aligned}
\mathrm{K}_{\text {gain }} & =\frac{\mathrm{O}_{2 \text { bottle,5 dbar }}}{\mathrm{O}_{2 \text { Optode,uncorrected, } 5 \text { dbar }}} \\
\mathrm{O}_{2} \text { Optode,gain corrected } & =\mathrm{K}_{\text {gain }} \mathrm{O}_{2} \text { Optode,uncorrected }
\end{aligned}
$$


where $\mathrm{O}_{2}$ optode,uncorrected, $5 \mathrm{dbar}$ is the uppermost uncorrected oxygen measurement from the float's first profile and $\mathrm{O}_{2}$ bottle, $5 \mathrm{dbar}$ is the deployment cast bottle oxygen measurement interpolated to the uppermost float pressure.

Applying this gain correction to each Optode, Figure 10d shows the residuals (as percent) of gain-corrected oxygen minus the deployment cast. Because the gain correction is set by the deployment cast 5 dbar oxygen value, the residuals are near zero in the mixed layer. We may ignore residuals in the thermocline and near the oxygen minimum because of sampling error. However, at pressures greater than $\sim 1000 \mathrm{dbar}$, the residuals are all negative, with values between 0 and $-5 \%$.

Figures $10 \mathrm{e}$ and $10 \mathrm{f}$ show the residuals for gain-correction minus oxygen-domain linear correction and gain-correction minus phase-domain linear correction, respectively.

\section{9c. Discussion}

Figures 11 and 12 show the oxygen profiles from the deployment cast and for the three methods discussed above. The figure also shows the float and deployment cast temperature profiles. For each float, 0-2000 dbar profiles are shown in the middle panels, along with expanded plots for the upper $100 \mathrm{dbar}$ (upper panels) and from about the oxygen minimum to $2000 \mathrm{dbar}$ (lower panels). Along with Figure 10, these figures show that the gain-corrected profiles agree extremely well (median/std $+0.00 \pm 0.3 \%(\mathrm{P}<50$ dbar)) with the deployment cast in the mixed layer, as the gain was set at $5 \mathrm{dbar}$. The mixed layer phase- and oxygen-domain linear corrected profiles also agree well $(-0.05 \pm 0.5 \%$ for phase domain; $+0.40 \pm 1.1 \%$ for oxygen domain) for most floats. There are mixed layer residuals of $\sim 2-3 \mu \mathrm{mol} \mathrm{kg}^{-1}$ for floats 5093 and 5071 , but the temperature profiles for these two floats also show significant differences, indicating that conditions in the mixed layer are dissimilar between the deployment cast and first profile.

In the deep layer, agreement with the deployment cast is fairly good for both linear corrections, with one outlier (UW float 5100 for oxygen-domain linear correction). For both linear corrections, the deep layer residuals vary fairly evenly around zero (Figures 10a and 10b). For P>1800 dbar, the residuals for oxygen-domain linear correction range from -0.54 to $+2.75 \%(\mu \pm 1 \sigma=+0.07 \pm 0.9 \%)$ while for phase-domain they range from $[-0.99$ to +0.41$](-0.03 \pm 0.3 \%)$. In contrast, Figure $10 \mathrm{~d}$ shows the gaincorrected residuals in the deep layer are consistently low. Residuals of gain correction minus deployment cast for $\mathrm{P}>1800$ dbar range from -3.52 to $-0.48 \%(-2.21 \pm 1.1 \%)$, with values throughout the deep layer being about 0.5 to $4.5 \%$ low. Note also that the lower panels in Figures 10, 11 and 12 show that residuals below the oxygen minimum, where temperature and oxygen variations are small, vary little with pressure, so that it is unlikely that the low biases at depth are pressure-related.

For both the linear and gain corrections, we estimate the error from measurements where $|\delta T|<0.02^{\circ} \mathrm{C}$, as we did in Section 5. These are listed in Table 5. The table shows estimated errors of -0.6 to $+0.9 \%$ (aggregate $+0.3 \pm 1.1 \%$ ) for phase-domain linear correction and -1.0 to $+1.4 \%$ (aggregate $+0.5 \pm 1.2 \%$ ) for oxygen-domain linear correction. For the gain-corrected oxygen the errors are larger and are all negative, with values of -0.5 to $-3.4 \%$ and an aggregate error of $-1.7 \pm 1.4 \%$.

We caution that these results are based on a very small sample size ( 8 floats), and that the deployment casts, because of proximity/time differences and other possible 
errors, are an imperfect reference. The small difference between oxygen-domain and phase-domain linear correction cannot be accurately assessed, as it is near the measurement error between the calibrated Optodes and deployment casts. As more data becomes available for floats with both deployment casts and air observations, these differences should be measured and reassessed. The results for gain correction appear to be larger, suggesting that $\mathrm{O}_{2}$ might not be accurately corrected by a single gain factor calculated at one depth. In particular, application of a gain factor calculated at or near the surface, where oxygen levels are high and temperatures vary, may result in significant errors at depth, where both oxygen levels and temperatures are low.

\section{Conclusions and discussion}

Aanderaa 3830 and 4330 oxygen Optodes deployed on profiling floats display biases of 0 to $-40 \mu \mathrm{mol} \mathrm{kg} \mathrm{kg}^{-1}(\sim-12 \%)$ when compared with ship-based bottle data. By recalibrating the sensors in situ, these errors can be reduced by an order of magnitude or more.

After in situ phase-domain calibration of 147 Optode floats deployed world-wide over 12 years, median differences to World Ocean Atlas (WOA) 2009 climatology were reduced from $\sim 6 \%$ to $\sim 1 \%$. For eight Argo floats deployed in the Indian and Pacific Oceans with deployment casts, aggregate estimated error was reduced from $8 \%$ to $0.3 \%$. Using six dual-Optode floats, the median inter-Optode precision of the calibrations independent of reference uncertainty was estimated to be $0.1 \pm 0.6 \mu \mathrm{mol} \mathrm{kg}^{-1}(\sim 0 \pm 0.2 \%)$. For nineteen floats with surface air observations, partial pressure of oxygen $\mathrm{P}_{\mathrm{O} 2}$ calculated from NCEP surface level pressures and $\mathrm{P}_{\mathrm{O} 2}$ calculated from in situ-calibrated Optode observations agreed within less than $\pm 2 \%$.

Comparisons of phase-domain linear correction and oxygen-domain linear correction, using eight floats with deployment casts, suggest differences within $\sim \pm 2 \%$, although an assessment of these differences is difficult because of a lack of sufficiently accurate reference data. We recommend that these small differences be revisited with data now being collected from floats with both ship-based deployment casts and continuous surface air observations. Empirical comparisons of surface gain correction with deployment casts found Optode profiles corrected near the surface to be consistently low by $\sim 0.5-4.5 \%$ at depths below the oxygen minimum. Again, these results should be verified with more data.

In situ phase-domain calibration provides a comprehensive, versatile methodology that can take advantage of the best available reference data, whether historical ship data, climatology, deployment casts, or air measurements. Deployment cast data are rarely collected for profiling floats, but can be used for either calibration or validation when available (e.g., for the Southern Ocean Carbon and Climate Observations and Modeling project (SOCCOM) [http://soccom.princeton.edu]).

Use of Optode air measurements is extremely promising, though it cannot be used for previously deployed Optode floats without surface air observations. Our method can be used for floats with or without this capability. For floats with surface air observations, our work suggests that use of surface air as the high oxygen reference, combined with either a WOD-based climatological reference or deployment cast as the low oxygen, low temperature reference, may be a viable approach. 
Work in the past several years to improve the accuracy of Optode-type oxygen measurements from profiling platforms has begun to produce results that allow ocean scientists to use oxygen data with some degree of confidence. Contributions by several groups have increased our understanding of the capabilities and limitations of luminescence quenching sensors to measure dissolved oxygen in the ocean. This work is now bringing oxygen into the growing set of biogeochemical variables usefully measurable from autonomous platforms. As accuracy improves, standard, consistent methods of calibration should be carefully evaluated and developed to provide users with consistent, high-quality data over the widest range of instruments and conditions.

\section{Acknowledgements}

We are grateful for support received from the National Science Foundation. This material is based upon work performed under NSF Grant Numbers OPP-1429342 and OPP-1353177.

\section{References:}

Aanderaa Instruments, 2003: TD218 Operating Manual, Oxygen Optode 3830 and 3930, $8^{\text {th }}$ edition.

Aanderaa Instruments, 2012: TD 269 Operating Manual, Oxygen Optode 4330, 4831, $4835,4^{\text {th }}$ edition.

Bittig, H., B. Fiedler, R. Scholz, G. Krahmann, and A. Körtzinger, 2014: Time response of oxygen optodes on profiling platforms and its dependence on flow speed and temperature, Limnol. Oceanogr. Methods 12, 2014, 617-636, DOI

10.4319/lom.2014.12.617

Bittig, H. C. and A. Körtzinger, 2015: Tackling oxygen optode drift: Near-surface and in-air oxygen optode measurements on a float provide an accurate in-situ reference, J. Atmos. Oceanic Technol., 32, 1536-1543, doi:10.1175/JTECH-D-14-00162.1

Bittig, H.C., Björn Fiedler, Peer Fietzek, Arne Körtzinger, 2015: Pressure Response of Aanderaa and Sea-Bird Oxygen Optodes. Journal of Atmospheric and Oceanic

Technology 32:12, 2305-2317.

Boyer, T., M.E. Conkright and S. Levitus, 1999: Variability of dissolved oxygen, percent oxygen saturation, and apparent oxygen utilization in the Atlantic and Pacific Oceans, Deep-Sea Research I 46,1593-1613.

Bushinsky, S. M., Emerson, S. R., Riser, S. C. and Swift, D. D. (2016), Accurate oxygen measurements on modified Argo floats using in situ air calibrations. Limnol. Oceanogr. Methods. doi:10.1002/lom3.10107

D'Asaro, E. A., and C. McNeil, 2013: Calibration and Stability of Oxygen Sensors on Autonomous Floats. J. Atmos. Ocean. Technol. 30: 1896-1906. 
Demas, J. N., B. A. De Graff, and P. Coleman, 1999: Oxygen sensors based on luminescence quenching. Anal. Chem., 71, 793A-800A.

Emerson, S., 1987: Oxygen cycles and biological new production in surface waters of the subarctic Pacific Ocean, J. Geophys.Res., 92(C6), 6535-6544, doi:10.1029/JC092iC06p06535.

Fiedler, Björn, Fietzek, Peer, Vieira, Nuno, Silva, Péricles, Bittig, Henry C. and Körtzinger, Arne, 2013: In situ CO2 and O2 measurements on a profiling float, Journal of Atmospheric and Oceanic Technology 30, 112-126. DOI 10.1175/JTECH-D-1200043.1.

García, H. E., and L. I. Gordon, 1992: Oxygen solubility in sea- water: Better fitting equations. Limnol. Oceanogr. 37, 1307-1312.

García, H. E., R. A. Locarnini, T. P. Boyer, J. I. Antonov, O. K. Baranova, M. M. Zweng, and D. R. Johnson, 2010. World Ocean Atlas 2009 Volume 3: Dissolved Oxygen, Apparent Oxygen Utilization, and Oxygen Saturation. S. Levitus, Ed., NOAA Atlas NESDIS 70, U.S. Government Printing Office, Washington, D.C., 344 pp.

Jenkins, W. J., and J. C. Goldman, 1985: oxygen cycling and primary production in the Sargasso Sea, J. Mar. Res., 43, 465-491.

Johnson, D.R., T.P. Boyer, H.E. García, R.A. Locarnini, O.K. Baranova, and M.M. Zweng, 2009: World Ocean Database 2009 Documentation. Edited by Sydney Levitus.

Johnson, K. S., J. N. Plant, S. C. Riser, and D. Gilbert, 2016. Air oxygen calibration of oxygen optodes on a profiling float array. Journal of Atmospheric and Oceanic Technology, 32, 2160-2172

McNeil, C.L. and E.A. D’Asaro, 2014: A calibration equation for oxygen optodes based on physical properties of the sensing foil. Limnol. Oceanogr. Methods 12:139-154 DOI: 10.4319/lom.2014.12.139

Kobayashi, T., T. Suga, and N. Shikama, 2006: Negative bias of dissolved oxygen measurements by profiling floats (in Japanese). Oceanogr. Japan 15, 479-498.

Körtzinger, A., J. Schimanski, and U. Send, 2005: High quality oxygen measurements from profiling floats: A promising new technique. J. Atmos. Oceanic Technol. 22, 302308.

Najjar, R. G., and R. F. Keeling, 1997: Analysis of the mean annual cycle of the dissolved oxygen anomaly in the World Ocean, J. Mar. Res., 55, 117-151.

Swift, J and A. Wong, 2007: Chief and Co-Chief Scientist's Report, R/V Roger Revelle

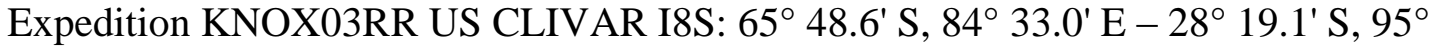
0.05' E 4 February - 17 March 2007 Port Calls: Dunedin, New Zealand, to Fremantle, Australia 
http://cdiac.ornl.gov/ftp/oceans/CLIVAR/I08S_2007.data/i08s_33RR20070204_do.pdf

Takeshita, Y., T. R. Martz, K. S. Johnson, J. N. Plant, D. Gilbert, S. C. Riser, C. Neill, and B. Tilbrook (2013), A climatology- based quality control procedure for profiling float oxygen data, J. Geophys. Res. Oceans 118, 5640-5650, doi:10.1002/jgrc.20399.

Uchida, H., T. Kawano, I. Kaneko, and M. Fukasawa, 2008: In Situ Calibration of Optode-Based Oxygen Sensors. J. Atmos. Oceanic Technol. 25, 2271-2281, doi: 10.1175/2008JTECHO549. 


\begin{tabular}{|cccccc|}
$\begin{array}{c}\text { UW float } \\
\text { ID }\end{array}$ & WMO ID & \multicolumn{2}{c}{$\begin{array}{c}\text { Deployment cast } \\
\text { calibration }\end{array}$} & \multicolumn{2}{c|}{$\begin{array}{c}\text { WOD } \\
\text { calibration }^{2}\end{array}$} \\
\hline & & $\mathbf{C s v}_{\mathbf{6}}$ & $\mathbf{c s v}_{\mathbf{7}}$ & $\mathbf{C s v}_{\mathbf{6}}$ & $\mathbf{~ c s v ~}_{\mathbf{7}}$ \\
\hline $\mathbf{5 0 9 2}$ & 4900487 & -7.203 & +1.238 & -7.077 & +1.234 \\
\hline $\mathbf{5 0 9 3}$ & 4900477 & -11.655 & +1.236 & -12.647 & +1.258 \\
\hline $\mathbf{5 0 9 4}$ & 4900476 & -8.177 & +1.248 & -8.062 & +1.246 \\
\hline $\mathbf{5 0 9 5}$ & 4900482 & -7.110 & +1.228 & -7.897 & +1.246 \\
\hline $\mathbf{5 0 7 1}$ & 4900474 & -12.109 & +1.245 & -12.390 & +1.253 \\
\hline $\mathbf{5 1 0 0}$ & 4900485 & -8.051 & +1.245 & -6.755 & +1.210 \\
\hline $\mathbf{5 0 7 2}$ & 4900475 & -8.737 & +1.243 & -9.607 & +1.264 \\
\hline $\mathbf{5 0 7 3}$ & 4900483 & -9.464 & +1.256 & -8.771 & +1.236 \\
\hline $\mathbf{5 0 3 4}$ & 5901069 & -9.906 & +1.236 & -9.990 & +1.227 \\
\hline $\mathbf{5 0 6 7}$ & 5901073 & -10.077 & +1.212 & -11.078 & +1.236 \\
\hline
\end{tabular}

Table 1. Stern-Volmer phase coefficients derived using deployment casts and WOD.

\begin{tabular}{|cccccc|}
$\begin{array}{c}\text { UW float } \\
\text { ID }\end{array}$ & WMO ID & $\begin{array}{c}\text { Proximity to } \\
\text { deployment } \\
\text { cast }\end{array}$ & $\begin{array}{c}\text { Factory } \\
\text { calibration }\end{array}$ & $\begin{array}{c}\text { In situ } \\
\text { calibration } \\
\text { ref = WOD }\end{array}$ & $\begin{array}{c}\text { In situ } \\
\text { calibration } \\
\text { ref = depl. cast }\end{array}$ \\
\hline $\mathbf{5 0 9 2}$ & 4900487 & $6 \mathrm{~km} 25 \mathrm{~h}$ & $-12.5(7 \%)$ & $-0.3(0.1 \%)$ & $-0.7(0.4 \%)$ \\
\hline $\mathbf{5 0 9 3}$ & 4900477 & $4 \mathrm{~km} 29 \mathrm{~h}$ & $-24.8(14 \%)$ & $-0.0(0.0 \%)$ & $-0.5(0.3 \%)$ \\
\hline $\mathbf{5 0 9 4}$ & 4900476 & $25 \mathrm{~km} 26 \mathrm{~h}$ & $-15.4(8 \%)$ & $+0.8(0.4 \%)$ & $+1.0(0.5 \%)$ \\
\hline $\mathbf{5 0 9 5}$ & 4900482 & $27 \mathrm{~km} 26 \mathrm{~h}$ & $-13.0(8 \%)$ & $+1.0(0.6 \%)$ & $+0.8(0.5 \%)$ \\
\hline $\mathbf{5 0 7 1}$ & 4900474 & $35 \mathrm{~km} 25 \mathrm{~h}$ & $-19.4(11 \%)$ & $+0.3(0.2 \%)$ & $+0.9(0.5 \%)$ \\
\hline $\mathbf{5 1 0 0}$ & 4900485 & $8 \mathrm{~km} 26 \mathrm{~h}$ & $-14.0(7 \%)$ & $-1.2(0.6 \%)$ & $-0.9(0.5 \%)$ \\
\hline $\mathbf{5 0 7 2}$ & 4900475 & $9 \mathrm{~km} 27 \mathrm{~h}$ & $-14.4(8 \%)$ & $+0.8(0.5 \%)$ & $+1.2(0.7 \%)$ \\
\hline $\mathbf{5 0 7 3}$ & 4900483 & $13 \mathrm{~km} 26 \mathrm{~h}$ & $-13.6(8 \%)$ & $+2.1(0.9 \%)$ & $+0.9(0.5 \%)$ \\
\hline Aggregate & & - & $-\mathbf{1 4 . 1}(\mathbf{8 \%})$ & $\mathbf{+ 0 . 6 ( 0 . 3 \% )}$ & $+\mathbf{+ 0 . 4 ( 0 . 2 \% )}$ \\
\hline
\end{tabular}

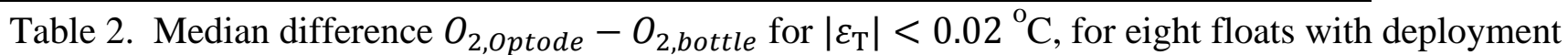
bottle casts, and for the aggregate. Values are in $\mu \mathrm{mol} \mathrm{kg}{ }^{-1}$. 


\begin{tabular}{|cccc|}
\hline UW float ID & WMO ID & $\begin{array}{c}\text { Factory } \\
\text { calibration }\end{array}$ & $\begin{array}{c}\text { In situ } \\
\text { calibration }\end{array}$ \\
\hline $\mathbf{7 6 6 1}$ & 5904024 & $-0.9_{ \pm} 1.8$ & $+0.1_{ \pm} 0.7$ \\
\hline $\mathbf{8 3 7 2}$ & 5904026 & $-0.2 \pm 0.5$ & $-0.1 \pm 0.3$ \\
\hline $\mathbf{8 3 8 1}$ & 5904028 & $+0.0 \pm 1.6$ & $-0.0 \pm 1.4$ \\
\hline $\mathbf{8 3 8 2}$ & 5904025 & $+2.5 \pm 1.1$ & $-0.1_{ \pm} 0.6$ \\
\hline $\mathbf{8 3 8 7}$ & 5904027 & $-2.1 \pm 1.3$ & $-0.4 \pm 1.0$ \\
\hline $\mathbf{8 3 9 7}$ & 5903743 & $+0.8 \pm 1.0$ & $-0.1 \pm 0.5$ \\
\hline Median & & $-\mathbf{0 . 1} \pm \mathbf{1 . 2}$ & $-\mathbf{0 . 1} \pm \mathbf{0 . 6}$ \\
\hline
\end{tabular}

Table 3. Inter-Optode differences for six dual-Optode floats. All in situ calibrations used reference $\mathrm{O}_{2}$ and $\% \mathrm{O}_{2}$ Sat based on WOD. Values are in $\mu \mathrm{mol} \mathrm{kg}$.

\begin{tabular}{|cccccc|}
$\begin{array}{c}\text { UW } \\
\text { float } \\
\text { ID }\end{array}$ & $\begin{array}{c}\text { WMO } \\
\text { ID }\end{array}$ & $\begin{array}{c}\text { Number } \\
\text { of } \\
\text { profiles }\end{array}$ & Dates of Operation & Deployment location & $\begin{array}{c}\text { PO }_{\mathbf{2}} \\
\text { \% error }\end{array}$ \\
\hline $\mathbf{0 0 6 8}$ & 5903717 & 177 & $20120219-20160502$ & $67.70 \mathrm{~S} 158.83 \mathrm{~W}$ & $+5.2 \pm 1.9^{*}$ \\
\hline $\mathbf{6 0 9 1}$ & 5904179 & 76 & $20140406-20160519$ & $57.33 \mathrm{~S} 169.84 \mathrm{~W}$ & $+0.2 \pm 0.9$ \\
\hline $\mathbf{6 9 6 7}$ & 5903612 & 223 & $20111211-20160321$ & $39.35 \mathrm{~S} 20.33 \mathrm{E}$ & $-0.8 \pm 1.2$ \\
\hline $\mathbf{6 9 6 8}$ & 5903718 & 248 & $20120306-20150921$ & $55.84 \mathrm{~S} 129.62 \mathrm{~W}$ & $-1.0 \pm 5.5^{*}$ \\
\hline $\mathbf{7 5 5 2}$ & 5903593 & 265 & $20120315-20151229$ & $44.39 \mathrm{~S} 106.89 \mathrm{E}$ & $+1.5 \pm 1.7$ \\
\hline $\mathbf{7 6 1 3}$ & 5904180 & 76 & $20140411-20160521$ & $65.41 \mathrm{~S} 155.80 \mathrm{~W}$ & $+1.5 \pm 3.0$ \\
\hline $\mathbf{7 6 1 4}$ & 5904183 & 74 & $20140411-20160502$ & $67.51 \mathrm{~S} 146.09 \mathrm{~W}$ & $+0.2 \pm 1.2$ \\
\hline $\mathbf{7 6 1 9}$ & 5904105 & 167 & $20130313-20160520$ & $63.72 \mathrm{~S} 153.70 \mathrm{E}$ & $+1.4 \pm 1.2$ \\
\hline $\mathbf{7 6 5 2}$ & 5904467 & 51 & $20141225-20160522$ & $60.76 \mathrm{~S} 3.17 \mathrm{E}$ & $-0.5 \pm 1.3$ \\
\hline $\mathbf{9 0 3 1}$ & 5904396 & 113 & $20140412-20160526$ & $52.31 \mathrm{~S} 128.34 \mathrm{~W}$ & $+0.5 \pm 1.1$ \\
\hline $\mathbf{9 0 9 1}$ & 5904184 & 76 & $20140414-20160525$ & $61.98 \mathrm{~S} 148.12 \mathrm{~W}$ & $+0.1 \pm 1.2$ \\
\hline $\mathbf{9 0 9 2}$ & 5904185 & 75 & $20140418-20160521$ & $60.24 \mathrm{~S} 117.77 \mathrm{~W}$ & $-0.2 \pm 1.0$ \\
\hline $\mathbf{9 0 9 4}$ & 5904471 & 51 & $20141221-20160520$ & $65.76 \mathrm{~S} 2.53 \mathrm{E}$ & $+0.1 \pm 1.1$ \\
\hline $\mathbf{9 0 9 5}$ & 5904188 & 112 & $20140415-20160515$ & $50.87 \mathrm{~S} 138.83 \mathrm{~W}$ & $+1.3 \pm 1.4$ \\
\hline $\mathbf{9 0 9 6}$ & 5904469 & 51 & $20141221-20160520$ & $54.10 \mathrm{~S} 0.31 \mathrm{E}$ & $+0.8 \pm 1.1$ \\
\hline $\mathbf{9 0 9 9}$ & 5904468 & 47 & $20150130-20160518$ & $65.03 \mathrm{~S} 3.17 \mathrm{E}$ & $-0.2 \pm 1.5$ \\
\hline $\mathbf{9 1 2 5}$ & 5904397 & 47 & $20150201-20160520$ & $60.78 \mathrm{~S} 2.92 \mathrm{~W}$ & $+0.2 \pm 1.5$ \\
\hline $\mathbf{9 2 6 0}$ & 5904473 & 47 & $20150207-20160526$ & $47.67 \mathrm{~S} 43.59 \mathrm{E}$ & $+0.3 \pm 0.8$ \\
\hline $\mathbf{9 2 7 5}$ & 5904472 & 42 & $20150129-20160327$ & $68.58 \mathrm{~S} 15.66 \mathrm{~W}$ & $+4.4 \pm 1.2^{*}$ \\
\hline
\end{tabular}

Table 4. Percent error of WOD-calibrated $\mathrm{P}_{\mathrm{O} 2}$ in air relative to NCEP-derived $\mathrm{P}_{\mathrm{O} 2}$ for UW floats with air measurement capability. "Marked entries have known calibration errors or large Optode drift. 


\begin{tabular}{|c|c|c|c|c|}
\hline float ID & WMO ID & $\underset{\text { Phase-domain }}{\text { linear correction }}$ & $\frac{\text { Oxygen-domain }}{\text { linear correction }}$ & $\frac{\text { Gain }}{\text { correction }}$ \\
\hline$\underline{5092}$ & 4900487 & $-0.1 \pm 1.0 \%$ & $-0.2 \pm 0.8 \%$ & $-0.9 \pm 0.9 \%$ \\
\hline$\underline{5093}$ & 4900477 & $-0.0 \pm 2.0 \%$ & $-0.3 \pm 2.1 \%$ & $-3.4 \pm 2.2 \%$ \\
\hline$\underline{5094}$ & 4900476 & $+0.4 \pm 1.2 \%$ & $+0.5 \pm 1.4 \%$ & $-1.7 \pm 1.0 \%$ \\
\hline$\underline{5095}$ & 4900482 & $+0.6 \pm 1.5 \%$ & $+1.4 \pm 1.1 \%$ & $-3.2 \pm 1.9 \%$ \\
\hline 5071 & 4900474 & $+0.2 \pm 0.7 \%$ & $-0.0 \pm 0.8 \%$ & $-0.5 \pm 0.7 \%$ \\
\hline$\underline{5100}$ & 4900485 & $-0.6 \pm 0.9 \%$ & $-1.0 \pm 1.5 \%$ & $-0.5 \pm 1.3 \%$ \\
\hline$\overline{\overline{5072}}$ & 4900475 & $+0.5 \pm 0.4 \%$ & $+1.1 \pm 0.6 \%$ & $-2.6 \pm 0.7 \%$ \\
\hline$\overline{\underline{5073}}$ & 4900483 & $\pm 0.9 \pm 0.5 \%$ & $+0.9 \pm 0.6 \%$ & $-1.5 \pm 1.2 \%$ \\
\hline Aggregate & & $+0.3 \pm 1.1 \%$ & $+0.5 \pm 1.2 \%$ & $-1.7 \pm 1.4 \%$ \\
\hline
\end{tabular}

Table 5. Median $\pm 1 \sigma$ percent difference $100 \times\left(O_{2, \text { optode }}-O_{2, \text { depl.cast }}\right) /$

$O_{2, \text { depl.cast }}$ for $\left|\varepsilon_{\mathrm{T}}\right|<0.02{ }^{\circ} \mathrm{C}$, using phase-domain linear correction, oxygen-domain linear correction, and surface gain correction. 
Figure 1. Stern-Volmer oxygen surface with data from float 5092, (a) without phase correction, and (b) with phase correction. Small circles represent calculated $\mathrm{O}_{2}$ float data with colors corresponding to the difference between calculated $\mathrm{O}_{2}$ and the Stern-Volmer oxygen surface. Large circles represent reference $\mathrm{O}_{2}$ samples from WOD casts along the float track at 20 dbar (cyan) and 1900 dbar (white).

Figure 2. Scatterplot of reference phase vs. raw phase used to calibrate UW Float 5092. Blue dots are deep layer (1900 dbar, low oxygen) data; green dots are surface layer (20 $\mathrm{dbar}$, high oxygen) data. The phase regression line and resulting phase coefficients are indicated.

Figure 3. (a) Float track for UW float 5092 (WMO 4900487). Black and colored circles indicate float profile locations. Blue, green and magenta circles indicate profiles compared to WOD-based references at $1900 \mathrm{dbar}\left(\mathrm{O}_{2}\right), 20 \mathrm{dbar}\left(\% \mathrm{O}_{2} \mathrm{Sat}\right)$, or both, respectively. Locations of WOD oxygen casts are shown as grey dots. (b) Scatterplot of Optode $\mathrm{O}_{2}$ vs. interpolated WOA $\mathrm{O}_{2}$ for factory calibration (green) and WOD-based in situ calibration (red), with median residuals indicated. (c) Optode $\mathrm{O}_{2}$ with factory calibration (d) Optode $\mathrm{O}_{2}$ with in situ calibration (e) $\mathrm{WOA} \mathrm{O}_{2}$ interpolated to float positions. See text for details.

Figure 4. (a) Oxygen profiles from UW float 5092 profile 1 and deployment cast (CLIVAR/Repeat Hydrography cruise I08S station 081). Green circles show the factorycalibrated values $\mathrm{O}_{2 \text { uncal }}$, red circles show the in situ-calibrated values $\mathrm{O}_{2 \text { cal }}$, and white circles show the deployment bottle cast values $\mathrm{O}_{2 \text { ship }}$. Residuals $\mathrm{O}_{2 \text { cal }}$ - $\mathrm{O}_{2 \text { ship }}$ are shown on the right side of the plot, with median average values listed for each of five pressure regions. (b) CTD temperatures and residuals for the same profile and cast.

Figure 5. Calibrated oxygen residuals vs. temperature residuals for UW float 5092 in the (a) mixed layer, (b) pycnocline, (c) mid-depth layer, (d) oxygen minimum layer, and (d) deep layer. Black dots are the residuals; dashed lines are the medians in each vertical zone. Gray boxes indicate the region of $\pm 1 \sigma$.

Figure 6. Tracks of floats with deployment casts. The green circle at one end of each trajectory marks the first profile.

Figure 7. Distribution of the difference between Optode oxygen and float-interpolated WOA climatology for 147 Optodes deployed on UW floats, using (a) factory calibration and (b) in situ calibration.

Figure 8. Comparison of WOD-based in situ-calibrated oxygen for six dual-Optode floats. 
Figure 9. (a) Partial pressure of oxygen in air for UW float 6967. The red line shows $\mathrm{P}_{\mathrm{O}_{2}, \text { Optode }}$ calculated from WOD-based calibrated oxygen. The green line shows $\mathrm{P}_{O_{2}, N C E P}$ calculated from NCEP surface level pressures (SLP). (b) Equivalent freshwater molar oxygen concentration from the Optode (red) and from $\mathrm{P}_{O_{2}, N C E P}$ (green) for float 6967. (c) $\mathrm{P}_{O_{2}, \text { optode }}$ (red) and $\mathrm{P}_{O_{2}, N C E P}$ (green) for UW float 6968 , showing possible drift.

Figure 10. Residuals (in percent) for UW floats 5092, 5093, 5094, 5095, 5071, 5100, 5072 and 5073 for (a) oxygen-domain linear correction minus deployment cast, (b) phase-domain linear correction minus deployment cast, (c) oxygen-domain linear correction minus phase-domain linear correction, (d) gain correction minus deployment cast, (e) gain correction minus oxygen-domain linear correction and (f) gain correction minus phase-domain linear correction. Solid black lines show pressure-binned median and median \pm 1 standard deviation for the eight floats.

Figure 11. Gain-corrected oxygen profiles (red) compared to phase-domain linear corrected profiles (light green), oxygen-domain linear corrected profiles (dark green dashed) and deployment casts (black dots) for UW floats 5092, 5093, 5094 and 5095. Also shown are temperature profiles from the float CTD (blue) and deployment cast (black dots). For each float, the 0-2000 dbar profiles are shown in the middle row of panels, along with expanded plots of the mixed layer (upper panels) and below the oxygen minimum (lower panels).

Figure 12. Same as Figure 11, for UW floats 5071, 5100, 5072 and 5073. 
